\title{
Full genome analysis of a novel type II feline coronavirus NTU156
}

\author{
Chao-Nan Lin • Ruey-Yi Chang • Bi-Ling Su • \\ Ling-Ling Chueh
}

Received: 13 September 2012/ Accepted: 3 December 2012/Published online: 14 December 2012

(c) Springer Science+Business Media New York 2012

\begin{abstract}
Infections by type II feline coronaviruses (FCoVs) have been shown to be significantly correlated with fatal feline infectious peritonitis (FIP). Despite nearly six decades having passed since its first emergence, different studies have shown that type II FCoV represents only a small portion of the total FCoV seropositivity in cats; hence, there is very limited knowledge of the evolution of type II FCoV. To elucidate the correlation between viral emergence and FIP, a local isolate (NTU156) that was derived from a FIP cat was analyzed along with other worldwide strains. Containing an in-frame deletion of 442 nucleotides in open reading frame $3 \mathrm{c}$, the complete genome size of NTU156 (28,897 nucleotides) appears to be the smallest among the known type II feline coronaviruses. Bootscan analysis revealed that NTU156 evolved from two crossover events between type I FCoV and canine coronavirus, with recombination sites located in the
\end{abstract}

Electronic supplementary material The online version of this article (doi:10.1007/s11262-012-0864-0) contains supplementary material, which is available to authorized users.

\section{C.-N. Lin}

Department of Veterinary Medicine, National Pingtung

University of Science and Technology, Pingtung, Taiwan

\section{R.-Y. Chang}

Department of Life Science, Institute of Biotechnology,

National Dong Hwa University, Hualien, Taiwan

B.-L. Su

Graduate Institute of Veterinary Clinical Sciences,

National Taiwan University, Taipei, Taiwan

L.-L. Chueh $(\bowtie)$

Graduate Institute of Veterinary Medicine,

National Taiwan University, Taipei, Taiwan

e-mail: linglingchueh@ntu.edu.tw
RNA-dependent RNA polymerase and M genes. With an exchange of nearly one-third of the genome with other members of alphacoronaviruses, the new emerging virus could gain new antigenicity, posing a threat to cats that either have been infected with a type I virus before or never have been infected with FCoV.

Keywords Type II feline coronavirus - Feline infectious peritonitis · Genome analysis · Virus recombination · Virus evolution

\section{Introduction}

Feline coronaviruses (FCoVs) are large, enveloped, positive-strand RNA viruses with a genome of approximately 29,200 nucleotides [1-3]. The FCoVs belong to the genus Alphacoronavirus, family Coronaviridae, order Nidovirales. Other members of this subgroup include canine coronavirus $(\mathrm{CCoV})$, transmissible gastroenteritis virus (TGEV), raccoon dog CoV (RDCoV/GZ43/03), and Chinese ferret badger CoV (CFBCoV/DM95/03) [4].

FCoVs are associated with diseases that range from subclinical and/or mild enteric infections to fatal infectious peritonitis [5]. Despite the high prevalence of FCoVs in feline populations around the world, only $5-12 \%$ of seropositive cats develop feline infectious peritonitis (FIP). FIP is a chronic, progressive, immune-mediated disease in domestic and nondomestic fields. The typical histopathological finding of this disease is systemic perivascular necrotizing pyogranulomatous inflammation [6]. Two serotypes that differ in their growth characteristics in tissue culture and in their genetic relationship to $\mathrm{CCoV}$ and TGEV have been identified [7, 8]. Type II FCoV is significantly correlated with FIP when compared to type I viruses $[9,10]$. However, unlike the 
ubiquity of type I FCoV, infection by type II virus encompasses only a small percentage of the total number of FCoVseropositive cats in different studies [9-16].

Type II FCoV is estimated to have diverged from alphacoronavirues in 1953 [4]. Based on partial genomic sequence analysis, type II FCoVs were suggested to result from a double recombination between type I FCoV and $\mathrm{CCoV}$ [17]. Like most RNA viruses, CoVs mutate at a high frequency due to the high error rate of RNA polymerization. In addition, a unique feature of $\mathrm{CoV}$ genetics is the high frequency of RNA recombination in the natural evolution of this virus [18]. Recombination among CoVs is an attribute of the genus and is thought to contribute to the emergence of new pathotypes, such as severe acute respiratory syndrome CoV [19, 20], human CoV NL63 (HCoV NL63) [21], HCoV HKU1 [22], and avian infectious bronchitis virus (IBV) [23-26]. To gain better evolutionary insight into type II FCoVs, we analyzed the complete genome of a novel type II FCoV isolate. Taking our data together with data from other strains, we discuss the evolution of type II FCoV.

\section{Materials and methods}

\section{Virus and isolation of viral RNA}

FCoV NTU156 was isolated in 2007 from a kitten with naturally occurring FIP by the co-cultivation of pleural effusion with feline fcwf-4 cells [27]. After three rounds of purification by limited dilution, the virus was propagated and titrated. All of the viruses used in this study for the sequencing of complete genome came from a stock virus passaged six times. NTU156 is relatively fast-growing, induces a coronavirus-typical syncytial cytopathic effect and is a type II FCoV [10].

Reverse transcription and PCR amplification of viral sequences

Eleven microliters of isolated RNA was added to the premix, consisting of $4 \mu \mathrm{l}$ of $5 \times$ RT buffer, $2.5 \mathrm{mmol}$ dNTPs (GeneTeks Bioscience, Inc., Taipei), 50 pmol random primer, $0.2 \mathrm{~mol}$ dithiothreitol, and $1 \mu \mathrm{l}$ of $200 \mathrm{U}$ Moloney murine leukemia virus reverse transcriptase (Invitrogen, CA, USA) in a $0.6 \mathrm{ml}$ reaction tube. This reaction mixture was then briefly centrifuged and incubated at $37{ }^{\circ} \mathrm{C}$ for $60 \mathrm{~min}$, then at $72{ }^{\circ} \mathrm{C}$ for $15 \mathrm{~min}$, and finally at $94{ }^{\circ} \mathrm{C}$ for $5 \mathrm{~min}$. A total of 120 primers for PCR were chosen from a relatively conserved region of the FCoV genome. Following reverse transcription, $1 \mu$ of the $\mathrm{RT}$ reaction mixture was added to $49 \mu \mathrm{l}$ of the PCR mixture, which consisted of $5 \mu \mathrm{l}$ of $10 \times$ Taq buffer, each primer (10 pmol), dNTP
(2.5 mmol), $2 \mathrm{U}$ of Taq DNA polymerase (GeneTeks, BioScience, Inc., Taipei), and $39 \mu \mathrm{l}$ of $0.1 \%$ DEPC water. An ABI-2720 thermal cycler (Applied Biosystems, USA) consisted of $3 \mathrm{~min}$ of preheating at $94{ }^{\circ} \mathrm{C}$, followed by 35 cycles of denaturation at $94{ }^{\circ} \mathrm{C}$ for $30 \mathrm{~s}$, annealing at $55^{\circ} \mathrm{C}$ for $30 \mathrm{~s}$, and extension at $72{ }^{\circ} \mathrm{C}$ for $1 \mathrm{~min}$ with a final extension at $72{ }^{\circ} \mathrm{C}$ for $7 \mathrm{~min}$. The viral RNA termini were amplified using $3^{\prime}$ - and $5^{\prime}$-rapid amplification of cDNA ends (Invitrogen, USA).

Analysis of PCR-amplified products and sequencing

A total of $10 \mu \mathrm{l}$ of PCR products from each PCR mixture was analyzed using a $1 \%$ agarose gel (Viogene, Taipei) for electrophoresis. Amplification products were visualized using UV illumination after ethidium bromide staining. The nucleotide sequences of the targeted DNA fragments were purified (Geneaid Biotech, Taipei) and sequenced in both directions using an auto sequencer (ABI 3730XL, USA). Full-length genome sequencing of NTU156 was performed by single-round PCR with a set of overlapping PCR products (average size $750 \mathrm{bp}$ ) that encompassed the entire genome.

\section{Sequence analysis}

The complete sequences of NTU156 were then compared with other alphacoronaviruses and the results are summarized in Table 1. Multiple alignments of nucleic acid sequences were performed by the Clustal W method using the MegAlign program (DNASTAR Inc., WI, USA). Phylogenetic analyses were conducted using MEGA, version 4.0. Similarity graphs were prepared with SimPlot 2.5 software [28]. Potential recombination sites were identified using the Recombination Detection Program (RDP) [29].

\section{Results}

Genomic sequence of FCoV NTU156

The full genomic RNA sequence of FCoV NTU156 comprises 28,897 nucleotides (nts), excluding the $3^{\prime}$ polyadenylated nts. Sequence analysis revealed that NTU156 contains conserved open reading frames with an overall genome organization similar to known FCoVs (Table 2). The overall nucleotide composition is as follows: A, $29.3 \%$; C, $17.3 \%$; G, $21.0 \%$; and T, $32.4 \%$. The G+C content is $38.3 \%$. NTU156 possesses the putative transcription regulatory sequence (TRS) motif, 5'-CUAAAC- $3^{\prime}$, at the $3^{\prime}$ end of the leader sequence and preceding each ORF (Table 2). 
Table 1 Isolation dates and accession numbers of NTU156 and other alphacoronavirses

\begin{tabular}{|c|c|c|c|c|c|}
\hline \multirow[b]{2}{*}{ Virus } & \multirow[b]{2}{*}{ Host } & \multicolumn{2}{|c|}{ Isolation } & \multirow[b]{2}{*}{ References } & \multirow[b]{2}{*}{ GenBank accession no. } \\
\hline & & Year & Country & & \\
\hline FCoV NTU156 ${ }^{\mathrm{a}}$ & Cat & 2007 & Taiwan & Lin [10] & GQ152141 \\
\hline FCoV NTU2 & Cat & 2003 & Taiwan & Unpublished & DQ160294 \\
\hline FCoV $79-1146^{a}$ & Cat & 1979 & USA & McKeirnan (1981) & DQ010921 \\
\hline FCoV Black $^{\mathrm{a}}$ & Cat & 1980 & USA & Black (1980) & EU186072 \\
\hline FCoV UU2 ${ }^{\mathrm{a}}$ & Cat & 1993 & USA & Unpublished & FJ938060 \\
\hline FCoV DF- $2^{\mathrm{a}}$ & Cat & 1981 & USA & Everman (1981) & JQ408981 \\
\hline FCoV C1Je ${ }^{a}$ & Cat & 2007 & UK & Dye [2] & DQ848678 \\
\hline FCoV $79-1683^{a}$ & Cat & 1979 & USA & McKeirnan (1981) & JN634064 \\
\hline FCoV KU-2 & Cat & 1991 & Japan & Hohdatsu (1991) & D32044 \\
\hline FCoV Yayoi & Cat & 1981 & Japan & Hayashi (1981) & AB695067 \\
\hline FCoV C3663 & Cat & 1994 & Japan & Mochizuki (1997) & AB535528 \\
\hline CCoV NTU336 ${ }^{\mathrm{a}}$ & Dog & 2008 & Taiwan & Unpublished & GQ477367 \\
\hline $\operatorname{CCoV} 1-71^{\mathrm{a}}$ & Dog & 1971 & Germany & Binn (1974) & JQ404409 \\
\hline CCoV TN-449 & Dog & $1980 \mathrm{~s}$ & USA & Unpublished & JQ404410 \\
\hline CCoV 174/06 & Dog & 2006 & Italy & Decaro (2009) & EU856362 \\
\hline TGEV Purdue $^{\mathrm{a}}$ & Pig & 1946 & USA & Doyle (1946) & DQ811789 \\
\hline TGEV M6 ${ }^{\mathrm{a}}$ & Pig & 1965 & USA & Bohl (1965) & DQ811785 \\
\hline TGEV TS $^{\mathrm{a}}$ & Pig & 2004 & China & Cheng (2004) & DQ201447 \\
\hline HCoV $229 \mathrm{E}^{\mathrm{a}}$ & Human & 1963 & & Hamre (1966) & AF304460 \\
\hline
\end{tabular}

${ }^{a}$ Full genome available

Table 2 Coding potentials and putative transcription regulatory sequences (TRS) of FCoV NTU156

\begin{tabular}{|c|c|c|c|c|c|}
\hline \multirow[t]{2}{*}{ ORFs } & \multirow{2}{*}{$\begin{array}{l}\text { Start-end (nucleotide } \\
\text { position) }\end{array}$} & \multirow[t]{2}{*}{ No. of nucleotides } & \multirow[t]{2}{*}{ No. of amino acids } & \multicolumn{2}{|l|}{ Putative TRS } \\
\hline & & & & Nucleotide position & TRS sequences \\
\hline ORF 1a & $313-2,417$ & 12,105 & 4,035 & 94 & GAACUAAACGAA210AUG \\
\hline ORF $1 \mathrm{ab}$ & $\begin{array}{l}313-20,417 \\
\text { (shift at } 12,381 \text { ) }\end{array}$ & 20,105 & 6,701 & & \\
\hline S & $20,414-24,775$ & 4,362 & 1,453 & 20,382 & UUACUAAACUUU23AUG \\
\hline ORF 3a & $24,840-25,076$ & 237 & 78 & 24,832 & GAACUAAACUUAUG \\
\hline ORF $3 b$ & $25,021-25,236$ & 216 & 71 & & \\
\hline ORF 3c & $25233-25,433$ & 201 & 66 & & \\
\hline $\mathrm{E}$ & $25,512-25,760$ & 249 & 82 & 25,469 & GUUCUAAACGAA37AUG \\
\hline M & $25,771-26,556$ & 786 & 261 & 25,762 & GAACUAAACAAAAUG \\
\hline $\mathrm{N}$ & $26,569-27,687$ & 1,119 & 372 & 26,557 & UAACUAAACUUCUAAAUG \\
\hline ORF 7a & $27,692-27,997$ & 306 & 101 & 27,684 & GAACUAAACGCAUG \\
\hline ORF $7 b$ & $28,002-28,622$ & 621 & 206 & & \\
\hline
\end{tabular}

$5^{\prime}, 3^{\prime}$ Untranslated regions (UTRs) and open reading frames (ORFs)

The 5'-UTR of FCoV NTU156 comprises 312 nts-one or two nts more than other known FCoVs (79-1146: 311 nts, black: 311 nts, C1Je: $310 \mathrm{nts}$ )—whereas the $3^{\prime}$-UTR of our virus comprises $275 \mathrm{nts}$, which is identical to other FCoVs. The $5^{\prime}$ two-thirds of the genome contain the $1 \mathrm{a}$ (nt 313-12,417) and 1ab (nt 313-20,417) genes that encode the nonstructural polyproteins. A typical coronavirus "slip site," $5^{\prime}$-UUUAAAC-3' (nt 12,381-12,387) is located within this gene. These genes are followed by genes encoding the four structural proteins: spike (nt 20,414-24,775), envelope (nt 25,512-25,760), membrane (nt 25,771-26,556), and nucleocapsid $(26,569-27,687)$ (Table 2). The two strings of accessory genes identified in all of the known FCoVs, 
i.e., ORF $3 \mathrm{ab}$ and ORF 7ab, were found in NTU156 as well (Table 2). However, an in-frame deletion of 442 nucleotides in ORF $3 \mathrm{c}$ was identified, which resulted in a relatively short gene comprising only $201 \mathrm{nts}$.

Genetic comparison and phylogenetic analysis with other alphacoronaviruses

The overall sequence comparison revealed that NTU156 was more closely related to known subgroup 1 a $\mathrm{CoV}$ but not $1 \mathrm{~b}$ within alphacoronaviruses (Fig. 1). Nucleotide sequences similarity graphs of NTU156 with known type I FCoVs, CCoVs, and TGEVs were created by the Simplot software. The results showed that NTU156 was more closely related to type I FCoVs from the $5^{\prime}$ end of the genome to position 15,000 and from position 27,500 to $3^{\prime}$-UTR (Fig. 2). Genes located at the $5^{\prime}$ end (nsp1-11) and $3^{\prime}$ end (the N gene through ORF7) of NTU156 show consistently high similarity to type I FCoVs, whereas from nsp13 through the E sequence, the similarity to canine and porcine CoVs varies dramatically (Fig. 3). These data indicate that NTU156 might have arisen from recombination events between different strains of $\mathrm{CoV}$ s from species other than cats. Two possible recombination sites, at approximate positions 14,300 and 27,300, corresponding to the RNAdependent RNA polymerase (RdRp) and the $\mathrm{M}$ gene, respectively (Fig. 4), were further analyzed.

Phylogenetic trees using the nucleotide sequence of genes for putative proteins and polypeptides of alphacoronaviruses were further constructed. At nsp 1 through nsp 11 (Supplementary Fig. 1a) and from N gene (Supplementary Fig. 1b) to the ORF 7ab gene (Supplementary Fig. 1c), NTU156 was more closely related to type I FCoVs. At the nsp 12 (RdRp) and the M gene, NTU156 was not clustered with any known alphacoronavirues (Fig. 3a, f). From the nsp13 through the E gene, NTU156

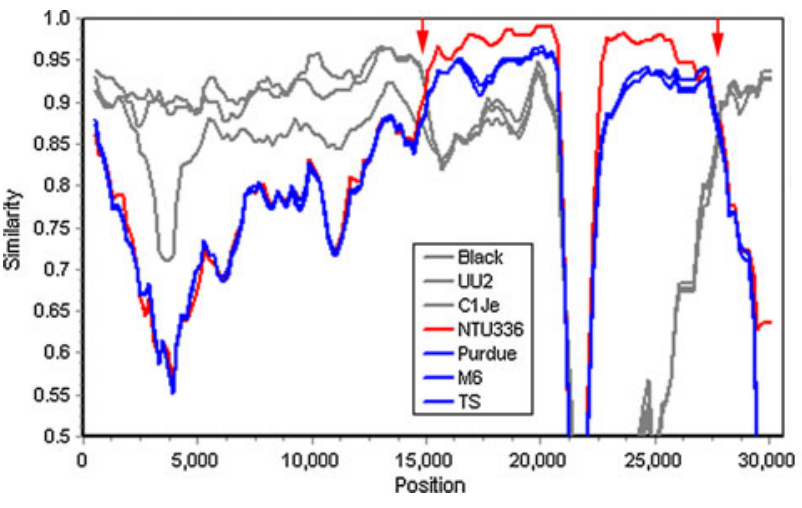

Fig. 2 Nucleotide sequence similarity of the complete genome of FCoV NTU156 with other alphacoronaviruses. A similarity plot was constructed to identify the sequence homology between type I FCoVs black, C1Je, and UU2 (gray); CCoV NTU336 (red); and TGEV purdue, M6, and TS (blue). Red arrows represent putative recombination regions. A similarity of 1.0 indicates regions that share $100 \%$ nucleotide identity. The similarity calculation was performed using the following parameters: a window size of $1,000 \mathrm{bp}$ and a step size of $200 \mathrm{bp}$ for the full-length sequence

was clustered with $\mathrm{CCoV}$ (Fig. 3b-e). Taken together, these data indicated that NTU156 might have evolved from two recombination events with $\mathrm{CCoV}$, with the sites of recombination located in the $\mathrm{RdRp}$ and $\mathrm{M}$ genes.

\section{Discussion}

A unique feature of $\mathrm{CoV}$ genetics is the high frequency of RNA recombination both in vivo and in vitro [18]. Here, an interspecies recombination between feline and canine $\mathrm{CoV}$ was identified in a viral strain NTU156, which was isolated from the pleural effusion of a FIP cat. This is the first time that evidence for natural recombination has been documented through the complete genome sequence analysis of type II FCoV. In 1998, Herrewegh et al., based on partial
Fig. 1 Phylogenetic relationships constructed using the complete genome sequences of FCoV NTU156 and other alphacoronaviruses. Analysis was performed using MEGA 4 software and neighbor-joining methods based on 1,000 replicates. Bootstrap support values greater than 90 are shown

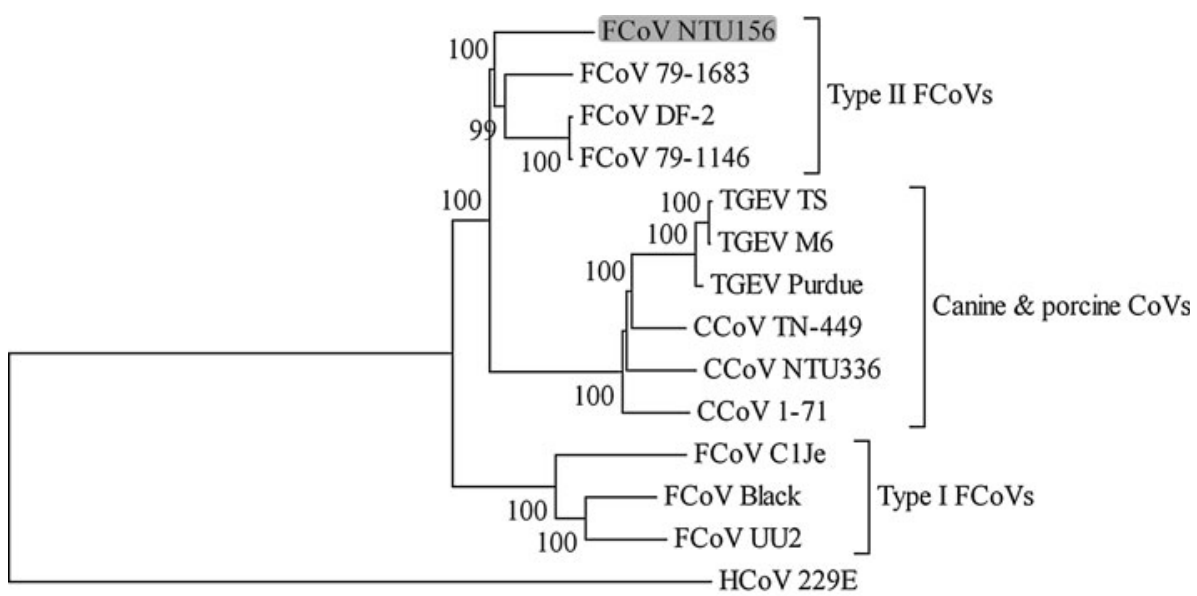

$\stackrel{\longmapsto}{0.02}$ 
a

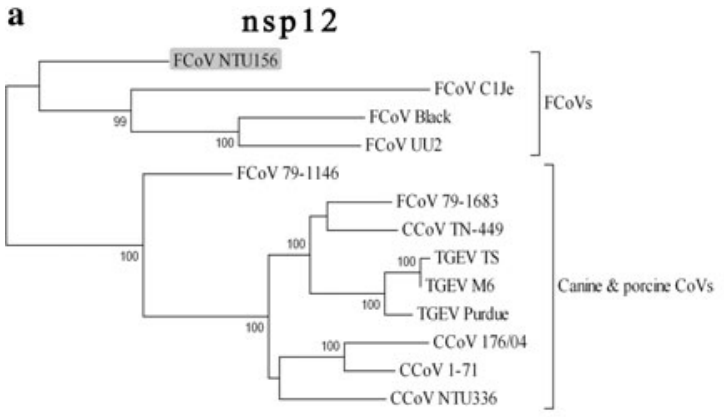

b $\stackrel{\stackrel{b}{0005}}{n s p 13-16}$

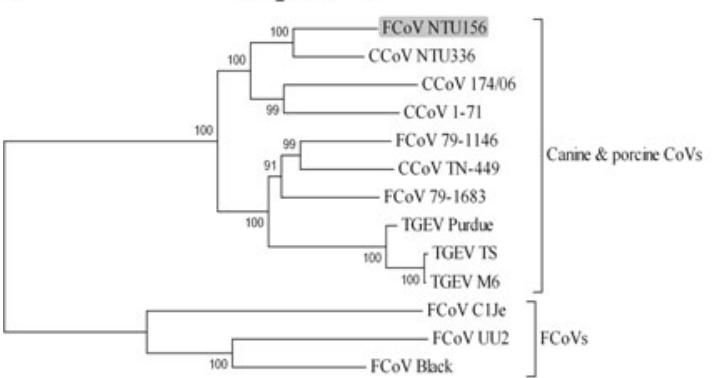
$\overrightarrow{0005}$

c S
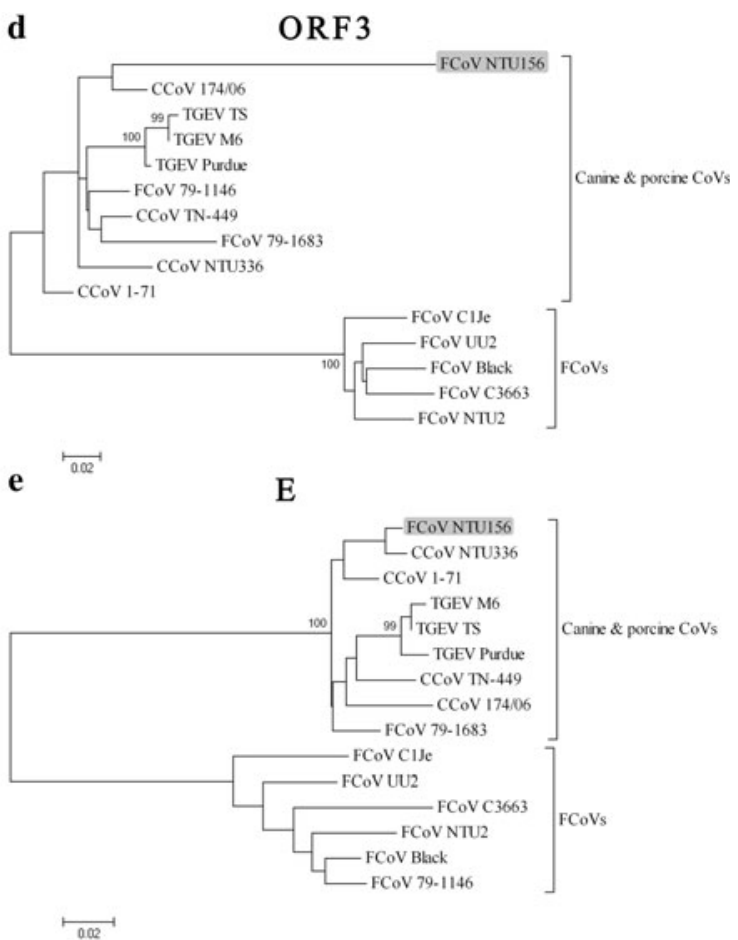

f

f $\quad \mathrm{M}$

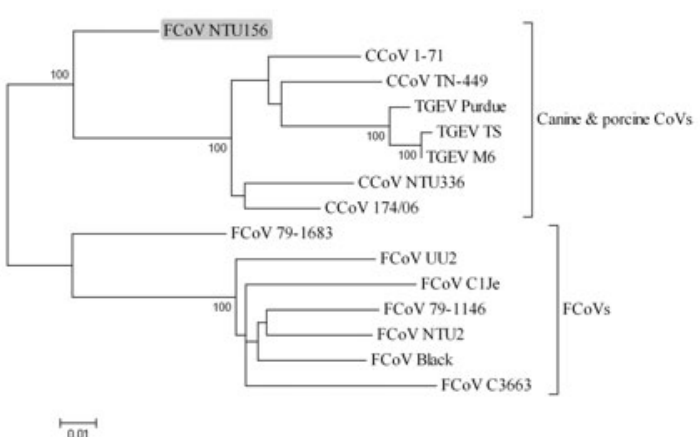

Analysis was performed using MEGA 4 software and neighborjoining methods based on 1,000 replicates. Bootstrap support values greater than 90 are shown

other type II FCoVs, genome crossovers with other alphacoronavirus were noted. When the sequences around the putative recombination sites were examined, i.e., one located in the $5^{\prime}$ region (strain 79-1146) and two in the $3^{\prime}$ region (strain 79-1146, and 79-1683), porcine coronavirus (TGEV) was also found to contribute to the evolution of type II FCoV (in addition to CCoV) (Figs. 3b, 5). This finding is not surprising because the receptor for type II FCoV, feline aminopeptidase $\mathrm{N}$, has been found to serve as a receptor for several CoVs, including canine, porcine, and human CoVs [30]. Therefore, the interspecies recombination of type I FCoV with any of the above viruses might occur in nature. The recombination of type I FCoV in cats 


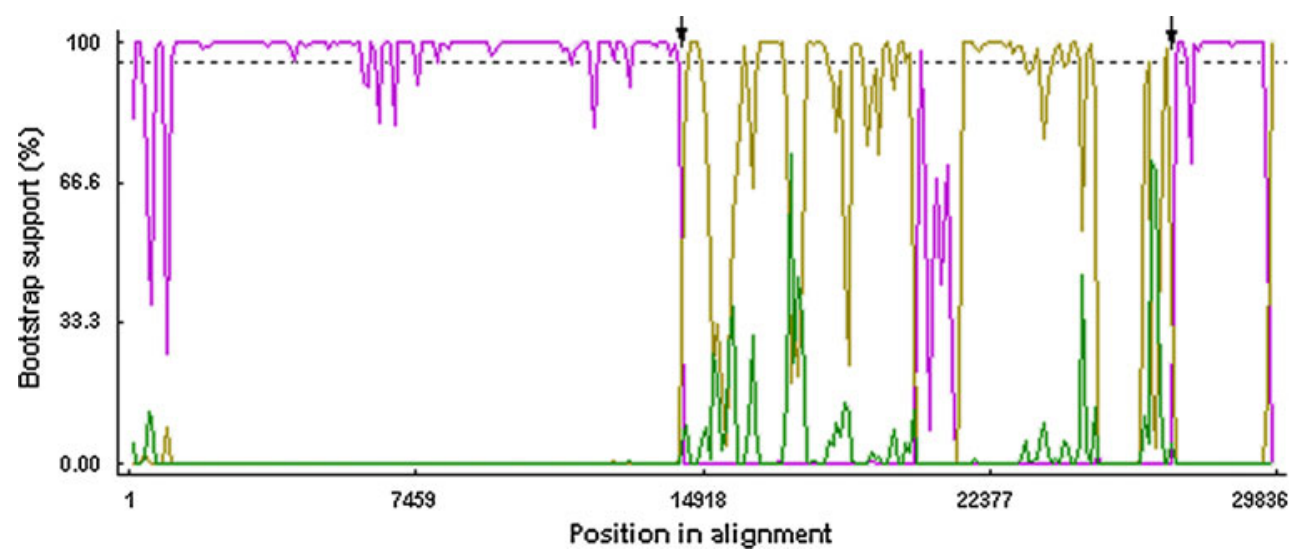

Fig. 4 Bootscan analysis of the complete genome of FCoV NTU156 with other alphacoronaviruses (type I FCoV UU2: pink; $\mathrm{CCoV}$ NTU336: yellow; TGEV purdue: green). Analysis was performed using RDP software and neighbor-joining methods based on 1,000

living in the same household with dogs or living close to pig farms could give rise to type II FCoV.

Based on the analysis of the four full genomes of type II FCoV available at present (NTU156, 79-1146, 79-1683, and DF-2), type II FCoVs appear to retain type I FCoV sequences in their $5^{\prime}$ and $3^{\prime}$ ends. We asked whether the genes located in these regions are indispensable for $\mathrm{FCoV}$ replication in cats. To answer that question, the amino acid sequence of genes retained at both ends of FCoVs, CCoVs, and TGEVs, i.e., nsp 1 through nsp 11 and the $\mathrm{N}$ and ORF7 genes, were further aligned and compared (Table 3). In contrast to the greater than $90 \%$ of amino acid homology between different strains of FCoVs, the nsp 2, 3, and 6, as well as the $\mathrm{N}$ gene and the ORF7a gene of FCoVs, when

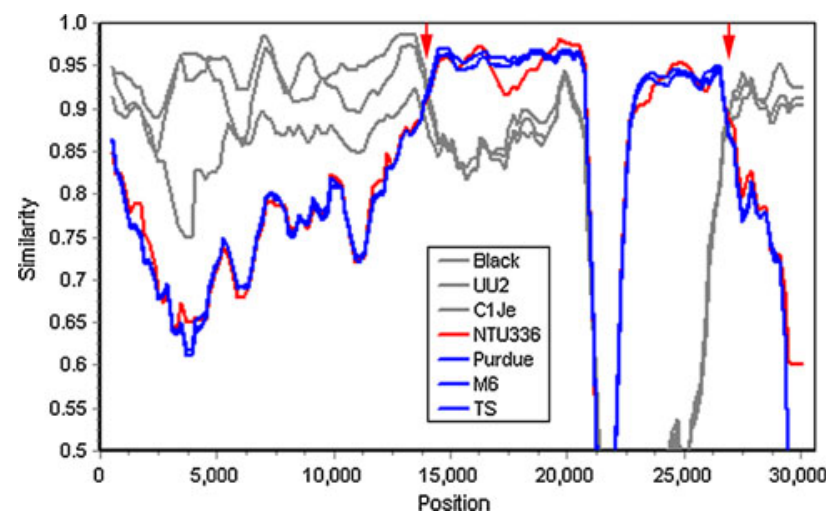

Fig. 5 Nucleotide sequence similarity of the complete genome of FCoV 79-1146 with other alphacoronaviruses. A similarity plot was constructed to identify the sequence homology between type I FCoVs black, C1Je, and UU2 (gray); CCoV NTU336 (red); and TGEV purdue, M6, and TS (blue). Red arrows represent putative recombination regions. A similarity of 1.0 indicates regions that share $100 \%$ nucleotide identity. The similarity calculation was performed using the following parameters: a window size of $1,000 \mathrm{bp}$ and a step size of $200 \mathrm{bp}$ for full-length sequences replicates. Putative recombination regions are indicated with arrow. The boostrap support calculation was undertaken using a window size of 1,000 bp and a step size of $200 \mathrm{bp}$. Dashed line indicates the $95 \%$ bootstrap support threshold values

compared with CCoVs or TGEVs, exhibited similarity of less than $80 \%$. This finding indicates that these gene products might possess irreplaceable functions for $\mathrm{FCoV}$ replication. This might explain why type II FCoVs found in nature harbor genomes that evolved from a double recombination.

Although the prevalence of type II FCoV is consistently lower $(2-11 \%)$ than type I virus around the world (88-98\%) [9-16], our previous study indicates that infection of type II FCoV correlates significantly with FIP

Table 3 Percent similarity with respect to the amino acid sequences of FCoV NTU156 and other alphacoronaviruses

\begin{tabular}{|c|c|c|c|c|c|c|c|}
\hline \multirow[t]{2}{*}{ Gene } & \multicolumn{3}{|l|}{ FCoV } & \multicolumn{2}{|l|}{$\mathrm{CCoV}$} & \multicolumn{2}{|l|}{ TGEV } \\
\hline & NTU2 & Black & C1Je & NTU336 & $174 / 06$ & Purdue & TS \\
\hline \multicolumn{8}{|l|}{ ORF1 } \\
\hline nsp1 & $-^{\mathrm{a}}$ & 93.6 & 92.7 & 91.8 & - & 92.7 & 91.8 \\
\hline nsp2 & - & 93.6 & 91.7 & 80.2 & - & 79.1 & 78.7 \\
\hline nsp3 & - & 91.5 & 84.9 & 79.2 & - & 78.8 & 78.3 \\
\hline nsp4 & - & 96.3 & 93.5 & 88.8 & - & 88.2 & 87.1 \\
\hline nsp5 & - & 97.4 & 96.7 & 93.4 & 93.4 & 93.0 & 92.7 \\
\hline nsp6 & - & 93.9 & 91.5 & 77.9 & 76.5 & 77.9 & 77.2 \\
\hline nsp7 & - & 97.6 & 97.6 & 97.6 & 96.4 & 96.4 & 96.4 \\
\hline nsp8 & - & 97.9 & 96.4 & 92.8 & 90.8 & 92.8 & 92.3 \\
\hline nsp9 & - & 95.5 & 96.4 & 86.5 & 91.0 & 89.2 & 89.2 \\
\hline nsp10 & - & 98.5 & 97.8 & 95.6 & 95.6 & 95.6 & 94.8 \\
\hline nsp11 & - & 94.7 & 100 & 84.2 & 84.2 & 84.2 & 84.2 \\
\hline $\mathrm{N}$ & 93.3 & 92.0 & 91.7 & 77.5 & 77.2 & 76.4 & 76.9 \\
\hline \multicolumn{8}{|l|}{ ORF7 } \\
\hline $7 a$ & 99.0 & 97.1 & 96.1 & 81.4 & 81.4 & 78.5 & 74.7 \\
\hline $7 b$ & 88.9 & 86.9 & 86.7 & 59.9 & 61.8 & - & - \\
\hline
\end{tabular}

${ }^{a}$ Not available 
when compared to type I [10]. As shown in the present study, type II FCoV arises by exchanging a large genome fragment (approximately $12 \mathrm{~kb}$ ) of type I FCoV with other members of alphacoronaviruses. The genes exchanged through this double recombination include nsp 13-16, structure protein $\mathrm{S}$ (spike), and accessory protein 3abc. The nsp 13-16 proteins are replication proteins with functions such as helicase activity (nsp 13), nucleoside triphosphatase activity (nsp 13), RNA $5^{\prime}$-triphosphatase activity (nsp 13), $3^{\prime}-5^{\prime}$ exoribonuclease activity (nsp 14), RNA cap formation (nsp 14 and nsp 16), and endonuclease activity (nsp 15) [31]. It has ben reported that the function of the $3 \mathrm{c}$ protein might be crucial for viral replication in the gut but is dispensable for systemic FCoV replication [32]. However, $\mathrm{S}$ proteins play a crucial role in receptor binding and eliciting protective immunity [33]. Through the replacement of nearly one-third of the genome, the new virus might gain new antigenicity, posing a threat to cats that either have been infected with a type I virus before or never have been infected with FCoV.

\section{References}

1. C. Dye, S.G. Siddell, J. Gen. Virol. 86, 2249-2253 (2005)

2. C. Dye, S.G. Siddell, J. Feline, Med. Surg. 9, 202-213 (2007)

3. G. Tekes, R. Hofmann-Lehmann, I. Stallkamp, V. Thiel, H.J. Thiel, J. Virol. 82, 1851-1859 (2008)

4. D. Vijaykrishna, G.J. Smith, J.X. Zhang, J.S. Peiris, H. Chen, Y. Guan, J. Virol. 81, 4012-4020 (2007)

5. N.C. Pedersen, J.F. Boyle, K. Floyd, A. Fudge, J. Barker, Am. J. Vet. Res. 42, 368-377 (1981)

6. N.C. Pedersen, J. Feline, Med. Surg. 11, 225-258 (2009)

7. N.C. Pedersen, J.W. Black, J.F. Boyle, J.F. Evermann, A.J. McKeirnan, R.L. Ott, Adv. Exp. Med. Biol. 173, 365-380 (1984)

8. N.C. Pedersen, J. Ward, W.L. Mengeling, Arch. Virol. 58, 45-53 (1978)

9. T. Hohdatsu, S. Okada, Y. Ishizuka, H. Yamada, H. Koyama, J. Vet. Med. Sci. 54, 557-562 (1992)

10. C.N. Lin, B.L. Su, C.H. Wang, M.W. Hsieh, T.J. Chueh, L.L. Chueh, Vet. Microbiol. 136, 233-239 (2009)

11. D.D. Addie, I.A. Schaap, L. Nicolson, O. Jarrett, J. Gen. Virol. 84, 2735-2744 (2003)
12. V. Benetka, A. Kubber-Heiss, J. Kolodziejek, N. Nowotny, M. Hofmann-Parisot, K. Mostl, Vet. Microbiol. 99, 31-42 (2004)

13. A. Duarte, I. Veiga, L. Tavares, Vet. Microbiol. 138, 163-168 (2009)

14. M. Kummrow, M.L. Meli, M. Haessig, E. Goenczi, A. Poland, N.C. Pedersen, R. Hofmann-Lehmann, H. Lutz, Clin. Diagn. Lab. Immunol. 12, 1209-1215 (2005)

15. N. Shiba, K. Maeda, H. Kato, M. Mochizuki, H. Iwata, Vet. Microbiol. 124, 348-352 (2007)

16. H. Vennema, Vet. Microbiol. 69, 139-141 (1999)

17. A.A. Herrewegh, I. Smeenk, M.C. Horzinek, P.J. Rottier, R.J. de Groot, J. Virol. 72, 4508-4514 (1998)

18. M.M.C. Lai, S. Perlman, L.J. Anderson, in Fields Virology, ed. by D.M. Knipe, P.M. Howley, D.E. Griffin, R.A. Lamb, M.A. Martin, B. Roizman, S.E.E. Straus (Lippincott Williams \& Wilkins, Philadelphia, 2007), pp. 1305-1335

19. C.C. Hon, T.Y. Lam, Z.L. Shi, A.J. Drummond, C.W. Yip, F. Zeng, P.Y. Lam, F.C. Leung, J. Virol. 82, 1819-1826 (2008)

20. J. Stavrinides, D.S. Guttman, J. Virol. 78, 76-82 (2004)

21. K. Pyrc, R. Dijkman, L. Deng, M.F. Jebbink, H.A. Ross, B. Berkhout, L. van der Hoek, J. Mol. Biol. 364, 964-973 (2006)

22. P.C. Woo, S.K. Lau, C.C. Yip, Y. Huang, H.W. Tsoi, K.H. Chan, K.Y. Yuen, J. Virol. 80, 7136-7145 (2006)

23. J.E. Brooks, A.C. Rainer, R.L. Parr, P. Woolcock, F. Hoerr, E.W. Collisson, Virus Res. 100, 191-198 (2004)

24. W. Jia, K. Karaca, C.R. Parrish, S.A. Naqi, Arch. Virol. 140, 259-271 (1995)

25. J.G. Kusters, E.J. Jager, J.A. Lenstra, G. Koch, W.P. Posthumus, R.H. Meloen, B.A. van der Zeijst, J. Immunol. 143, 2692-2698 (1989)

26. L. Wang, D. Junker, E.W. Collisson, Virology 192, 710-716 (1993)

27. C.N. Lin, B.L. Su, C.W. Wu, L.E. Hsieh, L.L. Chueh, Taiwan Vet. J. 35, 145-152 (2009)

28. K.S. Lole, R.C. Bollinger, R.S. Paranjape, D. Gadkari, S.S. Kulkarni, N.G. Novak, R. Ingersoll, H.W. Sheppard, S.C. Ray, J. Virol. 73, 152-160 (1999)

29. D.P. Martin, P. Lemey, M. Lott, V. Moulton, D. Posada, P. Lefeuvre, Bioinformatics 26, 2462-2463 (2010)

30. D.B. Tresnan, R. Levis, K.V. Holmes, J. Virol. 70, 8669-8674 (1996)

31. S. Perlman, J. Netland, Nat. Rev. Microbiol. 7, 439-450 (2009)

32. H.W. Chang, R.J. de Groot, H.F. Egberink, P.J. Rottier, J. Gen. Virol. 91, 415-420 (2010)

33. L. Du, Y. He, Y. Zhou, S. Liu, B.J. Zheng, S. Jiang, Nat. Rev. Microbiol. 7, 226-236 (2009) 